\title{
新时代华中师范大学国家级一流化学专业建设的思考与实践
}

万坚*，邓阳，原弘，余能芳，龚静鸣，李永健，温丽丽，张文华，郭能，李武客， 彭浩, 徐晖, 王成刚

华中师范大学化学学院, 化学国家级实验教学示范中心(华中师范大学), 武汉 430079

摘要: 面对新时代高等教育 “双一流” 建设的浪潮, 高等师范院校化学专业必须有自己的特色作为。以华中师范大 学化学专业(师范类)建设为例, 从人才培养目标、培养方案和课程群的构建, 课程的深度教学进化, 教学管理新体系 与新机制等三方面探讨了新时代国家级一流化学专业建设的相关问题、解决途径和实施方案与成效。

关键词: 高等师范院校; 一流化学专业; 专业建设

中图分类号: G64; O6

\section{The Research and Practice of the Development of the National First- Class Chemistry Major in Central China Normal University during the New Era}

Jian Wan *, Yang Deng, Hong Yuan, Nengfang She, Jingming Gong, Yongjian Li, Lili Wen, Wenhua Zhang, Neng Guo, Wuke Li, Hao Peng, Hui Xu, Chenggang Wang

National Experimental Chemistry Teaching Center, College of Chemistry, Central China Normal University, Wuhan 430079, China.

\begin{abstract}
Faced with the wave of "Double First-class" construction of higher education in the new era, chemistry major in higher normal university must create their own characteristic projects. Taking the development of chemistry major of Central China Normal University as an example, the national first-class construction of chemistry major in the new era were discussed from three aspects: The first aspect was the construction of objectives, programs and the formation of curriculum groups; the second aspect was the in-depth pedagogies; and the last aspect was related to the creation of management systems and mechanisms.
\end{abstract}

Key Words: Higher normal university; First-class of chemistry major; Major construction

推进高等院校 “双一流” 建设是新时代我国高等教育发展的指南针和风向标, 如何高质量地建 设一流专业, 是从人才培养的角度实现 “双一流” 建设目标的关键问题。高等师范院校作为培养未 来教师的重要基地, 其一流专业建设具有自身的特点。党的十九大以来, 我国相继出台的《关于全 面深化新时代教师队伍建设改革的意见》等一系列文件, 为优先发展教育事业、做强做大教师教育 事业进行战略部署, 是高等师范院校一流专业建设的重要纲领。新时代高等师范院校一流专业建设 不能在已有经验和工作基础上进行增减或修补，必须要系统地开展调研、论证和实践。

高水平人才培养体系的建立、国家级一流本科专业的建设要处理好六大关系。第一是学科建设

收稿: 2020-07-10; 录用: 2020-07-20; 网络发表: 2020-07-27

“通讯作者, Email: Jianwan@mail.ccnu.edu.cn

基金资助: 国家级一流本科专业建设点项目(2019 年度); 教育部高等学校化学类专业教学指导委员会教学研究课题(H20200506) 
与专业建设的关系。人才培养体系涉及学科体系、教学体系、教材体系、管理体系、思想政治工作 体系, 其中一流学科体系建设要为人才培养体系起到支撑作用, 反过来, 人才培养又是一流学科建 设的重要任务和人力资源来源。第二是教育教学理念与教学育人实践的关系。教育教学理念是教学 育人实践的思想指导, 反过来, 教学育人实践又能够支持教育教学理念的凝练与改进。通过教育教 学理念与教学育人实践的双向互动关系, 要确立 “全面发展、因材施教、强基固本、融合贯通、学 思践悟、知行合一、面向未来、追求卓越” 的本科人才培养理念, 以及 “五育为宗、学生为本、教 师为先、五术为魂、学科为基” 的本科教育工作理念。第三是课程教学与学科研究的关系。课程教 学必须体现出学科的基本知识结构、学科思维、学科理解、学科表达、学科问题解决, 通过体现学 术性以增强课程教学的高阶性、创新性和挑战度。反过来, 教师在课堂教学中, 特别是与学生的交 流互动中可以进一步发现新的学术问题、学术观点, 形成问题解决方案。应该说, 课程教学是教师 德术、学术、技术、艺术、仁术 (五术) 的综合体现, 是成为 “四有好老师”, 做到 “八个相统一” 的 “主战场” 和 “责任田”。第四是学科团队与课程团队的关系。要认识到科教融合对于创新人才的 培养具有决定性作用, 必须要将学科团队和课程团队的建设统筹起来, 将教师科研绩效和育人绩效 统一起来, 做到教学和科学研究相匹配、相适应、相得益彰。第五是专业建设与质量文化的关系。 专业内涵建设是专业建设的根本要求, 而建立专业建设的质量文化, 形成专业内外部质量监控闭环 则是专业建设的制度保障。二者的协调统一能够使得专业建设得到评估和反馈、持续改进, 实现良 性发展。第六是国家战略政策体制机制与高校人才培养模式的关系。要认识到培养学生适应并胜任 中国特色社会主义的建设和发展是中国高等教育育人之魂, 必须要在国家教育政策的指引下对人才 培养形成最优解。这一点对于高等师范院校特别重要, 在公费师范生培养不断完善的政策、机制与 培养模式的调控下, 利用贯通培养、交叉复合培养等方式提升人才培养质量, 才能够满足于基础教 育对高质量教育师资的需求和新时代对于大国良师的需要。

基于上述六大关系, 本文旨在以华中师范大学化学专业(师范类)建设为例, 讨论如何开展高等 师范院校一流化学专业建设的思考与实践。

\section{1 确立核心素养导向的人才培养目标、培养方案和课程群}

专业建设的关键是落实国家立德树人根本任务, 确立人才培养目标。首先, 必须将培养德智体 美劳全面发展的社会主义建设者和接班人这一目标贯穿于专业建设的全过程, 引导学生在专业成长 过程中扣好人生的第一粒扣子, 加强理想信念教育、社会主义核心价值观教育、中华优秀传统文化 教育、劳动教育和实践教育。其次, 鉴于当前国家教育发展需要和学生发展实际状况, 确立单一的 专业人才培养目标既不符合时代发展的要求, 也不契合学生多层次、多方向发展的实际。相反, 必 须根据国家战略需求和人的全面发展观, 设置多个类别的人才培养体系。

据此, 华中师范大学化学专业(师范类)分别设置了 “化学教师” (U2S)方向和 “数字化卓越化学 教师” (U2R)方向(U 代表 University, S 代表 School, R 代表 Research), 其中, “化学教师” 方向旨 在直接为中学培养基础教育骨干化学教师和教育管理者, “数字化卓越化学教师” 方向旨在为系统建 立 “本科-教育硕士-教育博士”一体化人才培养体系奠定坚实基础, 面向未来教育, 致力于培养教 学技能水平高、教育研究能力强、适应信息化时代教育发展的卓越化学教师。

基于系统调研、专家论证, 确定了化学专业(师范类)人才培养目标。需要明确的是, 当前各类人 才发展要求呈现出多样化、交叉化的趋势, 而常规的高等教育人才培养很难满足上述需求。反过来, 只有抓住个体成长成才的关键要素, 才能够使得高等教育人才培养更加有的放矢。为此, 化学专业 (师范类)人才培养目标旨在突出对学生核心素养的培养, 即以培养适应未来各类化学教师发展需要 的必备品格和关键能力为目标。另外, 由于两类人才培养方向有差异, 因此, 在确定核心素养导向 的人才培养目标时, 既要考虑共同核心素养, 又要考虑各方向侧重、高阶的核心素养。

从共同核心素养的角度看, 主要包括道德情操、职业情怀、身心体魄和化学学科基本素养四个 
方面, 均体现了在化学专业内部落实立德树人根本任务的关键要素。其中, 道德情操方面包括品性 修养、家国情怀、社会关怀、人格修养和文化修养五个要素, 旨在培育学生的道德修养, 助力于社 会主义核心价值观的养成。职业情怀方面包括职业信念、职业精神、职业态度和职业价值观四个要 素, 旨在让学生建立良好的师德、师风、师范, 助力于将 “政治素养、品格素养、专业素养、职业 素养” 的一体化发展。身心体隗包括健全人格、人际关系和身体素质、审美情操、劳动观念和实践 能力五个要素, 旨在化学专业充分彰显 “五育并举” 的培养总目标, 助力于育人实效性的提升。化 学学科基本素养包括化学学科基本知识、理论、技能; 化学学科思维和通过化学研究对世界进行理 解和决策的能力三个要素。

从各方向侧重、高阶的核心素养的角度看, “化学教师” 方向主要涉及现代教育学与化学教育学 基本知识与理论、化学教学技能和通过研究解决实际化学教学问题的能力三个要素, “数字化卓越化 学教师” 则在前者基础上增加数字化化学资源制作与运用能力、引领互联网 + 化学教育的能力和通过 规范、科学的研究解决实际化学教学问题的能力三个要素。

在 2020 年抗击新冠肺炎疫情的过程中，好的教师既能够增强 “四个意识”、坚定 “四个自信”、 做到 “两个维护”, 让学生体会到社会主义制度在人类共同抗击重大灾害中的巨大优势, 又能够准确 理解学生学习和全面发展的意义和特点, 主动开展生命教育、危机教育, 善于基于信息技术和教育 教学的融合来为学生的学习提供支持。这一事件充分表明化学(师范类)专业人才培养目标具有基础 性、时代性和多维性, 既要契合当前我国高等院校落实思想政治教育的要求, 体现 “四有好教师” 的内涵要素, 同时又要展现化学学科和化学教育学科对化学教师培养的基础性作用, 满足不同类别 学生的发展需求, 契合时代和社会发展对教师的需求。

我们基于核心素养框架, 完成了各方向人才培养方案及其创新课程体系的建设, 构建了具有高 度模块化、功能化、融合化、立体化的 “通识类+专业主干类 + 个性发展类” 课程群, 将共性和个性 培养有机整合。其中, 通识类课程着重培养学生对社会的认知和责任感; 专业主干类课程注重发展 学生化学学科思想、思维等高水平专业素质; 个性发展类课程主要突出实践能力、批判思维和创新 精神的培养。具体来说, 在 “化学教师” 方向建立了基于化学教师职业发展特征的课程群, 在 “数 字化卓越化学教师” 方向建立了体现师范性、学术性、数字化深度融合的 “数字化卓越化学教师” 课程群 ${ }^{[1]}$ 。需要说明的是, 高师院校化学专业课程群的构建, 既要遵循《化学类专业教学质量国家标 准》《高等学校化学类专业指导性专业规范》《化学类专业化学理论教学建议内容》《化学类专业化学 实验教学建议内容》等文件的专业性要求, 还要落实《普通高等学校师范类专业认证实施办法(暂行)》

《中学教育专业认证标准(第三级)》等关于师范教育文件的指示, 是一个相对复杂的设计、开发和实 践过程, 必须做好课程设计和课程内容的取舍、权衡、协调。例如, 在国家和学校规定的总学分内, 要在相对成体系的化学课程系统内增加教育学、心理学、教育技术学和化学教育学等相关课程, 就 必须要适当压缩化学课程系统的容量。这就需要统筹优化各门课程的内容, 减少不必要的重复, 提 高课程的教学质量。

\section{2 结合课程组教师团队建设, 实施课程群深度教学}

高等师范院校化学专业必须践行课程深度教学的理念。所谓课程深度教学, 不是指在课程中简 单增加教学内容的深度和难度, 而是真正做到教学要素系统化, 在知识教学的过程中突出学科思想、 学科思维和学科方法的培养。

实施课程深度教学的关键是课程组教师团队建设。通过本科教学创新奖评选、校(院)两级主干 课程团队优秀运行评估、各级教师竞赛、五类 “金课” 建设、课程组责任教授选聘等一系列措施, 建设了一支教学水平与学术造诣高、结构合理、具有国际化水平的教学团队, 从而实现了深度教学 理念和方法的落地。

深度教学首先要厘清教和学的关系。传统的高校教学常常将知识从真实的情境中剥离、抽象出 
来, 并根据学术逻辑进行简单组织, 形成课程。学生以班级为组织形式被分配到一起, 同一班级的 学生按照统一的设计速度和时间进行学习, 通过考试(考核)获得相应的课程学分。在课堂上, “教师 讲、学生听” 的 “讲座式” 教学成为常态, 教师努力在 “教” 的环节上下功夫, 考虑教的内容、进 度、方式、效果, 甚至为提高教学效率将教学内容进行灌输, 所谓的 “符号暴力” 屡见不鲜。为实 现人才培养目标, 落实人才培养方案, 需要转变上述的传统教学常态, 必须突出 “以学定教” 的理 念, 实现从 “以教师为中心” 到 “以学生为中心” 的教学转变。注重系统化地开展教学, 努力将 “课 程目标层次化” “教学内容国际化” “教学方法现代化” “教学环境信息化” “教学评价多元化” “研究 教学系统化”等六 “化” 融入教学的全过程。

在具体的课程教学中, 以 “知识与技能的深度学习过程” 为载体, 着重培养学生逻辑思维、批 判性思维、独立思考能力、教育教学能力、化学学科思维与表达能力。针对不同学科、不同模块的 课程, 需要采用不同的课程深度教学策略。

在结构化学课程群的教学中, 构建并实施了一套适合结构化学课程群的、以能力培养为导向的 不同阶段的教学方法与策略。在结构化学专业基础课程教学中, 为了帮助学生建立学科知识的系统 性, 要求学生通过口头报告和研讨(Oral presentation and discussion)进行学科知识框架凝练(Schema) 和解决挑战性问题(Challenge question)的训练, 构建实施了 SC@O 的教学策略与方法, 注重学生逻 辑、独立、批判性思维和 STEM (Science, Technology, Engineering, Mathematics)素养的培养 ${ }^{[2]}$ 。在理 论与计算化学、分子模拟基础等专业高阶选修课程教学中, 实施 “社会问题导向的、基于课程课题 的、注重过程评价的 $\mathrm{P}^{3} \mathrm{OBE}$ (Problem Oriented, Project-Based, Process-Evaluated Teaching and Learning) 教学方法与策略, 引导学生进一步掌握化学学科的理论基础, 培养学生的化学学科思维、科学表达 以及应用能力与素养 ${ }^{[3]}$ 。此外, 利用 “数字化 $3 \mathrm{D}$ 虚拟现实” 等现代信息化技术, 将相关基本理论知 识有机整合、重组再造, 形成虚拟仿真实验项目, 构建时时、处处、人人的线上学习环境, 在专业 基础课程和高阶课程中间搭起一座 “学思践悟” 的数字化学习桥梁。

物理化学课程群的教学坚持以 “四个转变” 为指导, 以学生发展为中心, 以 “典型” 任务立体 驱动教与学, 充分调动学生的学习积极性, 培养学生良好的学习习惯和学习能力。通过学生自主学 习、互助学习, 师生共同学习, 以期实现学生的深度学习, 用科学的思想和方法推进学生 “物理化 学” 核心素养的养成。将信息化技术与课堂教学深度融合, 帮助教师高效教学、科学评价的同时, 训练学生的信息化思维以及信息整合能力等。针对课程内容的特点开展教学, 对原理性内容, 追本 溯源, 以典型实例启发学生思考如何抽象概念, 从学生的心里引导出科学真理, 进而分析前人抽象 出概念的科学内核, 同时辅以大家的研讨理解抽象概念的可改进之处, 引导学生 “从无到有” 地正 确认识、理解、掌握基本概念和核心规律, 帮助学生构建理论基石。对应用型内容, 采用 “同一主 题多组主讲” 的模式, 各小组按抽签顺序讲解但内容不得重复, 激发学生良性竞争, 在教师的引导、 点拨下以 “小问题” 的挑战推进学生对课程认识理解的波浪式前进、螺旋式上升, 在思维交锋中使 学生整合学科内容、建构认知体系。再辅以绘制思维导图、视频习题讲解等活动, 引导学生从看似 杂乱无序的知识点、知识群之间建立关联, 以点成线、成面、成网络, 以富有层次感、逻辑性的知 识体系融入学生的原有认知框架中, 建构物理化学大厦。整个教学过程中从学生人才成长的角度, 以好奇心为根本驱动, 把学校学习自然过渡到终身学习, 培养学生的创新意识和创新能力。最后再 通过现代物理化学、催化化学、电化学等高阶课程的学习, 丰富和深化对物理化学学科的理解和认 识。总之, 通过本课程群的教学, 让学生把物理化学的知识、方法、思想融入灵魂, 并能指导生活 实践奠定未来科学人生的坚实基础。

在分析化学课程群的教学中, 根据学生特点和学科特性, 构建并实施了一套适合分析化学课程 群的、以核心素养为导向的教学方法与策略。为帮助学生主动建构分析化学各个知识点之间的相互 关联, 架构从传统经典的以化学反应为基础的化学分析到以物质的物理/物理化学性质为基础的仪器 分析, 从常量分析到微量/痕量分析的分析化学的完整知识脉络, 贯穿以导学单为载体, 设置以 “思 
维导图” 为教学环节, 开发并实施以问题引领(Problem Oriented)的 PO4S 教学策略和方法。按照从 情景导学(Situational-guidance, 提出问题), 至自主探究(Self-exploration, 分析讨论问题), 再至精讲 释疑 (Succinct-explanation, 解决问题), 最后总结提升 (Summary-promotion, 问题升华)的教学模式实 施教学过程 ${ }^{[4]}$ 。结合信息化多媒体手段, 开展师生/生生互动, 以线上/线下的讨论方式, 引导学生变 被动学习为主动学习, 掌握化学学科的基础理论, 获取经思考、查阅、问题辨析、总结凝练和灵活 应用的积极学习体验。同时, 将学习过程中对知识的理解、组织、应用和创造这一复杂的脑力活动, 通过思维导图的形式展现出来, 有利于学生构建完整的分析化学学科知识框架, 对学生的分析、归 纳、演绎和对比等逻辑思维能力的培养大有禆益, 注重学生的学科思维、科学表达以及应用能力与 素养的培养。

在无机化学课程群的教学中, 以化学知识的讲解为依托, 注重让学生理解蕴含在化学概念、原 理和结论之中的科学观点和方法, 逐步理解科学发展中的创新过程, 学习科学发展过程中的辩证思 想, 传授给学生科学研究的基本思想和方法, 培养学生科学创新的能力和精神。我们提出了五个“一” 和五个 “十” 的教学法。具体来说, 五个 “一” 包括理解一本书——教科书, 通过课前预习、课堂双 向互动、课后复习和作业等环节深入理解教科书; 读懂一本书——参考书, 深化对基本化学理论的 理解和扩大知识面, 鼓励阅读英文版参考书; 了解一段化学发展史或一位杰出化学家, 由此认识部 分教材内容的来历和化学家的巨大奉献精神; 利用互联网阅读一篇与所学内容相关的文献, 学会利 用互联网获得化学最新研究进展的信息, 并利用研讨课报告其理解的文献内容; 写出一篇专题报告, 通过阅读文献, 提升快速获得和提炼所需信息的能力, 以及写作的能力。五个 “十” 包括做一套可 能有十种答案或解释的思考题, 让新生知道在大学的课程学习中, 许多问题并不是只有唯一的答案; 做十套没有标准答案的练习, 由此发现大学功课中的练习并不是总有标准解答; 找出书上和授课内 容中的十处错误、不准确或不严谨之处, 敢于质疑教材内容和老师的讲课内容; 针对所学内容, 提 出挑战老师的十个问题在研讨课上讨论, 通过发现和提出问题, 以及由互联网等资源获得解答这些 问题的线索, 加深对所学内容的理解; 提出十个与化学有关的设想或妙思, 在不违背化学基本原理 的前提下，充分发挥自己的想象力，提出奇妙的设想。

在化学专业实践课程群的教学中, 以有机化学实验课程为例, 教师根据化学研究的基本过程, 开发了基于 “文献阅读-实验-实验论文写作-同伴评价-线上讨论” 为主线的课程实施方案。学生在 完成了每一次实验后都需要基于科学论文的形式撰写实验论文。学生实验论文写作的过程并不是基 于传统实验报告的书写方式, 而是在教师系统实施 “文献阅读” “同伴评价” 和 “线上讨论” 三项教 学干预后完成的。我们的教学研究表明, 这种实验课程教学方式对于学生实验论文写作的规范性、 客观性和逻辑性的部分方面有积极影响。其中, 在课程伊始, 阅读相关文献对于学生在实验论文写 作的规范性和逻辑性方面有积极影响, 表现为学生能够知道实验论文的组成要素, 清楚如何有逻辑 地组织文本。在课程实施过程中, 同伴对实验论文进行互评, 有助于学生更加合理地呈现实验仪器 和药品、真实地展现实验过程。不仅如此, 他们还更加关注数据的准确性, 考虑相关证据的充分性、 相关性和合理性。另外, 线上讨论有助于学生更有效地理解每个化学实验的目的, 更加关注实验结 论和证据之间的关系, 准确地解读实验过程中的产率和非预期现象 ${ }^{[5,6]}$ 。

在化学教学论课程群的教学中, 由于教育科学与自然科学在学科性质上存在差异, 使得学生必 须要转变学科观念, 学会从多角度探究和分析化学教育教学问题。基于论辩的教学策略可以有效地 帮助学生对相关问题进行深入思考。在论辩教学前, 首先给学生呈现所要论辩的主题(如 “不同版本 中学化学教科书的比较” )和具体问题(如 “以 “氯气” 这一内容为例, 分析人教版、苏教版、鲁科版 高中化学教科书的呈现方式, 判定并说明何种呈现方式最佳, 同时阐明如何在教学中利用教科书开 展教学”, 让学生在独立思考后完成对该问题的书面回答。在论辩教学中, 教师先引导持有不同观 点的学生分享观点, 再组织全班学生结合自己的看法和他人的主张进行论辩, 从而使其厘清各个观 点的建构过程和面对具体教育教学问题时多重观点的合理性。在论辩教学后, 让学生在自己课前的 
书面回答上进行修改和完善, 使自己对该问题和系列问题的理解丰富化、完整化、体系化。学生的 期末考试成绩表明, 能够在论辩前后对自己书面回答进行修改和完善的学生在相关类型的题目的作 答上均能够表现出色, 说明其已经逐渐掌握了探究和分析化学教育教学问题的思想、思维和方法。

基于华中师范大学信息化教学优势, 在课程深度教学的过程中, 着力于信息化教学环境的建设, 注重在智慧教室中基于云课堂等技术与课堂教学深度整合。特别是在实验教学方面, 构筑并不断完 善了 “虚实结合、虚为实用” 的化学实验教学体系, 积极打造了夯实基础、强化能力、激发创新的 “互联网 + 化学实验教学中心” 升级版, 助力于 “数字化卓越化学教师” 方向人才的培养。

此外, 在专业建设过程中以 “三个产出、三个支撑、三个评价” 为工作重心, 而在 “三个评价” 中尤其注重课程目标达成度评价标准的建立与实施。注重过程性评价和终结性评价相结合, 内部评 价与外部评估相结合, 教师评价和学生自评相结合, 力求实现课程评价与课程目标、毕业要求、培 养目标达成度评价相匹配、相支撑。

\section{3 统筹专业建设各要素, 建立健全教学管理的新体系和新机制}

高等师范院校一流化学专业建设需要专业各方面力量形成合力。教学委员会、各级领导、各研 究所(课程组)必须齐抓共管, 统筹兼顾, 确保专业建设管理制度化、育人过程一体化。

通过 “三・三・三・三” 新机制的建立, 构建学院 “三全育人” 的新格局, 为专业建设的质量提供 了制度机制保障。“三・三・三・三” 新机制即指建立学院教学委员会、研究所、主干课程团队的三级 教学负责体制; 建立由校级督导员、院级督导员以及学院党政班子成员组成的三级教学督导体制; 建立由主讲教师、学习小组、个人自我组成的三级学习管理和评价体制; 建立由辅导员、班主任、 导师组成的三级人生发展指导育人机制。“三・三・三・三” 新机制的有效贯彻落实, 保障了高等师范 院校一流化学专业建设的良性发展, 实现了整个教育教学环节对教师、学生、教研团队的综合性、 形成性、发展性评价。与 “三・三・三・三” 新机制一道建立的, 还有相关的教学管理制度(如专业主 干课程建设运行方案、主干课程优秀运行评估制度、课题组导师制度、班主任制度等)。这些管理制 度的有效运行确保了教学运行的规范化。

教学管理的新体系和新机制促使高等师范院校一流化学专业建设在多个方面实现了突破和创 新。首先, 思政育人体系得到进一步巩固和升华。除了对学生开展常规的思想政治教育以外, 通过 “课程思政” “学科思政” “活动思政” 等方式让化学和化学教育的思政育人功能充分体现并落地。 学生在具体的课程学习中, 在参与各类学科活动的过程中, 能够充分认识到化学学科的思想体系、 文化内涵、社会价值, 体会到成为一名优秀化学教师所必须具备的理想信念、道德情操、扎实学识 和仁爱之心。有机化学课程组认真贯彻落实全国高校思想政治工作会议精神, 全面理解 “思政课程” 向 “课程思政” 转变的时代背景, 主动探索 “课程思政” 实施的有效途径, 坚持将思想引领和价值 观塑造融入到有机化学专业教学中, 主动挖掘专业课程的思政元素, 紧紧围绕 “立德树人” 根本任 务, 推进构建 “三全育人” 格局。为打造 “课程思政” 专业教师团队, 凝聚有机化学课程育人合力, 课程组成员们勤思考、共协作、用巧力、出新招。做到齐心共创 “课程思政” 新思路, 加强顶层设 计, 让 “课程思政” 进课前; 提炼融合方法, 让 “课程思政” 驻课堂; 反思教学过程, 让 “课程思 政” 留课后。通过丰富教学案例, 树立学生三观; 总结教学效果, 促进学生发展; 落实教学目的, 提高学生素质来合作共享 “课程思政” 新成效。经过两年来课程组在有机化学课堂上进行的 “课程 思政” 教学实践, 凝聚出属于有机化学课程组的课程思政建设的典型思路、典型做法及案例等 “课 程思政” 智慧结晶。例如, 在抗击新冠肺炎疫情期间的线上有机化学课程教学中, 教师让学生为父 母烹饪一道充满爱的菜有, 记录烹饪过程、效果和反馈, 并以有机化学实验报告的形式进行提交, 既体现了有机化学学科研究的特色, 又融入了劳动教育的元素, 让学生树立起了积极的劳动观念, 增进了与家人之间的感情, 提高了生活技能。

其次, 学术育人体系得到进一步发展和提升。一些认为培养化学教师不需要使其具备扎实的化 
学学科学术基础的观点愈发站不住脚, 这是因为许多关于 PCK (Pedagogy Content Knowledge, 学科 教学知识)的研究表明化学专业师范生需要具备扎实的化学学科基础知识, 同时在对化学学科深度理 解的基础上发展相关的化学教学知识。郑长龙 ${ }^{[7]}$ 指出, 在中学化学教育要突出 “素养导向” 的化学教 学, 就必须让教师具备扎实的学科理解。因此, 进一步发展和提升高等师范院校一流化学专业的学 术育人体系显得尤为重要。各专业教师必须要在培养学生化学学科能力和学术水平上形成合力, 既 注重在课程教学中彰显学科性和学术性, 又要积极组织学生参与各类科研创新项目、研究性实验, 使其能够走进化学实验室、走进化学学科、走进化学研究, 逐步深谙化学学科的思想真谛、实践品 性和学术价值。

再者, 实践育人体系得到进一步充实和完善。在实验教学方面, 教师结合科研特色、学科特色 和教师教育特色, 把高水平的科研成果转化为实验教学内容, 将成熟的科研技术和方法引入实验教 学过程, 积极推进实验教学改革。在教师教育技能培训方面, 扎实推进包括中学化学教学实践案例 资源、中学化学虚拟实验教学、中学化学实验教学资源、中学化学教师论坛四大部分的化学教师教 育的平台建设, 为学生顺利走上教师岗位, 适应信息化时代教育教学改革发展需求提供了高效的催 化剂。在教育实习方面, 努力构建 “合作共建、资源共享、联合培养、优势互补、共同发展” 的协 同育人新机制, 通过联合培养、优势互补、共生发展, 在促进师范生教育实习工作高质量开展的同 时, 整合中学优秀的教育教学力量和资源, 为实现高素质创新型卓越教师的培养目标打下了坚实的 基础。

通过不解努力, 华中师范大学一流化学专业建设和一流化学学科建设相辅相成, 相得益彰。在 化学学科建设方面, 华中师范大学化学学科国际 ESI 排名从 2012 年的 466 位上升至 2018 年的 266 位, 2018 年进入 USNews (美国大学综合排名)全球大学化学学科排名世界前 300 强。在化学专业建 设方面, 2018 年化学(师范)专业顺利完成部属师大首批师范专业认证(第二级), 专业建设成果荣获 2018 年国家级教学成果奖二等奖和湖北省高等学校教学成果一等奖, 2019 年获批国家级本科一流 专业建设点。学科和专业真正实现了相互促进, 进入了良性循环的一流学科建设的轨道。

\section{参 考 文 献}

[1] 邓阳, 万坚. 大学化学, 2018, 33 (9), 33 .

[2] 万坚. 大学化学, 2017, 32 (4), 11.

[3] 万坚, 任彦亮, 饶立, 魏林, 李永健, 邓阳, 孟祥高, 原弘. 大学化学, 2020, 36 (1), 2003066.

[4] 龚静鸣, 张文华, 李芳, 徐晖, 周燕平, 梁沛, 熊博, 高婷娟, 原弘, 万坚. 大学化学, 2019, 34 (6), 26.

[5] Deng, Y.; Kelly, G. J.; Xiao, L. Chem. Educ. Res. Pract. 2019, 20, 270.

[6] Deng, Y.; Kelly, G. J.; Deng, S. Int. J. Sci. Educ. 2019, 41, 1408.

[7] 郑长龙. 课程·教材·教法, 2019, No. 9, 120. 